InVisible Culture • Issue 33: After Douglas Crimp

\title{
After Douglas Crimp \\ Questionnaire Response: \\ Zheng Bo
}

Zheng Bo

Published on: Jan 05, 2022

DOI: $10.47761 / 494 \mathrm{a} 02 \mathrm{f} 6.29 \mathrm{fg} f \mathrm{fb} 3$

License: Creative Commons Attribution 4.0 International License (CC-BY 4.0). 


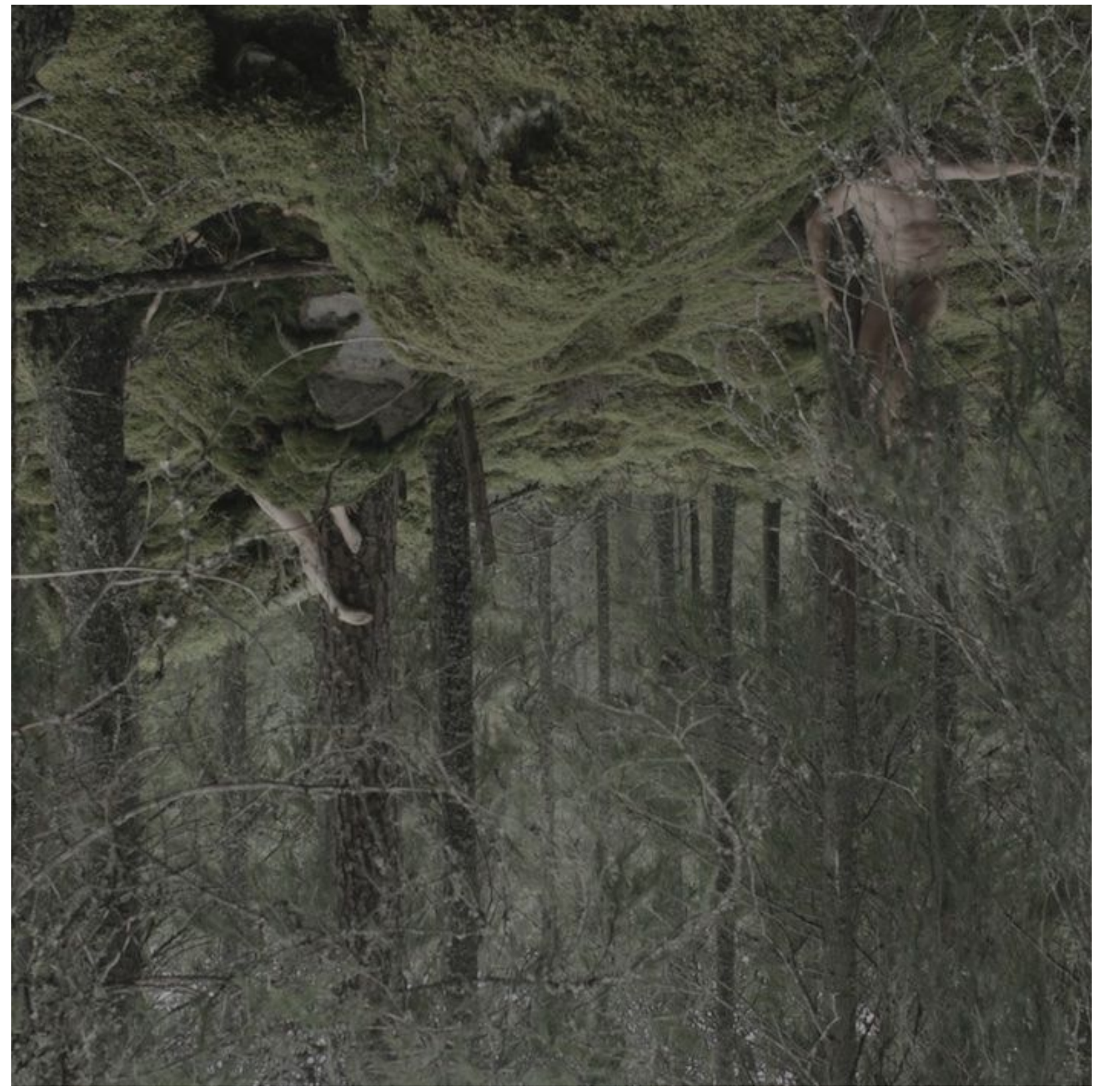

Zheng Bo grows weedy gardens, living slogans, eco-queer films, and wanwu workshops to cultivate ecological wisdom beyond the Anthropocene extinction.

$\underline{\text { Click here to return to the other questionnaire responses. }}$ 